Gómez Amich, M. (2016). The untold story: June's case study. Linguistica Antverpiensia, New Series: Themes in Translation Studies, 15, 89-105.

\title{
The untold story: June's case study
}

\author{
María Gómez Amich \\ University of Granada, Spain \\ mgamichtrad@gmail.com
}

Undoubtedly, Secret Intelligence Services' stories are based on people. And so is this article, which presents a new insight through a unique testimony from a narrative interview of an MI6 veteran linguist whose existence was kept highly guarded for more than 40 years. Drawing on first-hand testimony and a range of historical publications, this article presents a thematic study of key details about the decoding, translating and indexing activities performed by MI6 veterans. It is interwoven with data collected from a three-and-a-half hour interview which was subsequently manually analysed according to keywords and themes. Owing to the small corpus, this article does not seek to draw any conclusions but rather to serve as a tribute to all those who worked with languages at MI6 sections during World War II.

\section{Introduction}

According to Jeffery (2010), "[t]he British Secret Intelligence Services (SIS) - popularly known as MI6 ${ }^{1}$ [Military Intelligence, Section 6] - is the oldest continuously surviving foreign intelligence-gathering organization in the world" (p. ix). Founded in 1909, it became a valuable branch of the British state and played a paramount role in supervising Bletchley Park's (BP's) work and triumphs over the breaking ${ }^{2}$ of the German cyphering code during World War II.

A great deal has been written about the British SIS during this historical period, focusing particularly on BP - the Secret Service war site (Dryden, 2001, p. 197) considered as a paramount section of the MI6 and the Government Code and Cypher School (GCCS) (Calvocoressi, 1980; Erskine \& Smith, 2011; Hinsley \& Stripp, 2001; Lewin, 1978; Paterson, 2008; Smith, 2011; Welchman, 1982). However, the study and the analysis of the translation activity during these years - even though most of the messages decoded ${ }^{3}$ were in a foreign language - have not been presented in any of these research publications.

It is estimated that, thanks to BP, World War II was ended two years earlier than expected. However, it is undeniable that without an activity that would make decoded messages understandable to recipients, this would have never been possible. Raw intelligence is non-operational, 
and lacks any kind of strategic potential if users are not able to understand the message. Therefore, and due to the foreignness of the intelligence (Footitt \& Tobia, 2013, p. 29), translation became of vital importance during this time (Footitt \& Tobia, 2013, p. 30). Linguists, therefore, were the key link between raw intelligence and its users, and were therefore responsible for having developed a translation-evaluation-analysis process (Footitt \& Kelly, 2012, p. 32). This article focuses on this process, and pursues the objectives to:

- $\quad$ present languages as integral to the constitution and development of World War II;

- contextualize languages within the specifics of World War II, as well as the linguist's position in intelligence translation, evaluation and analysis at MI6, with special focus on BP and GCCS;

- $\quad$ shed some light on MI6 linguists, based on a first-hand story;

- $\quad$ engage others in further research projects related to languages in conflicts and, especially, during World War II.

The methodology chosen to collect the data for our study followed a qualitative approach, that is, the narrative interview, which allows our subject to feel encouraged to tell a story about some significant event in her life. Following this methodology, data was collected during a threeand-a-half hour narrative interview and keywords (background, recruitment, trustworthiness, secrecy, training, duties, translation, evaluation and overall experience) were identified in topic-related literature. Data were then manually categorized and analysed as per identified coded keywords and later on contrasted with the study's hypothesis for June's case, that is:

- World War II was a breeding ground for translators and interpreters, and as a result

- $\quad$ linguists were recruited based on the law of supply-and-demand and specific skills were learnt in the field;

- $\quad$ therefore, the positions held by linguists required wide adaptation to random contexts, as it still happens in certain interpreting spheres nowadays, for example, conflict zones.

This article does not, however, include the subject's whole interview, but rather presents key extracts from the encounter. For that, the categorizing strategy known as "thematic analysis" and described above was applied through an inductive approach in which theory was developed based on extracted data.

The interwoven-categorized data hereby presented allow us to provide first-hand information regarding the profile, recruitment, training, duties and overall experience of a veteran MI6 linguist. This, in turn, sheds some light on a figure whose existence was kept highly guarded 
and was not officially acknowledged by the British government until 1994, when formal legal consent to do so was given by the Intelligence Services Act of 1994 (Jeffery, 2010, p. x).

\section{Languages in conflict}

The issue of languages in conflict - especially the critical role during the intelligence-gathering and analysis stages - had rarely been addressed until Footitt and Kelly edited the book Languages at War in 2012. In it, the authors analysed not only the place of languages during predeployment (intelligence) but also in the preparation, support and on-theground experiences.

As a contribution to this relatively new research field, this article focuses on two of the stages of conflict preparations and operations: intelligence-gathering and analysis during World War II. In doing so, it will cover Sigint rather than Humint. According to NATO (2012, p.9) Sigint is " $[t]$ he generic term used to describe communications intelligence and electronic intelligence [...]", whereas Humint refers to information collected and provided by human sources. Sigint therefore comprises the cryptanalysis and intelligence analysis for which language translation plays a critical role due to the foreignness of intercepted messages.

\subsection{Languages and linguists during World War II: June's case study}

During World War II, Allied armies had the mission to liberate enemyoccupied territories and undoubtedly the success of their mission was the result of thorough intelligence. To hold any value, such intelligence is known to only a particular group of insiders who must keep it a secret (Kupcikas, 2013). During World War II, in order to have access to the gist of such intelligence it was vital to rely on a team of linguists able to "cancel" the foreignness intrinsic in such messages and transform them into valuable and highly secret intelligence. Such secrecy was a main part in everyone's daily life and it was well represented all over Great Britain with popular posters reading "Careless talk costs lives" such as the one below: 


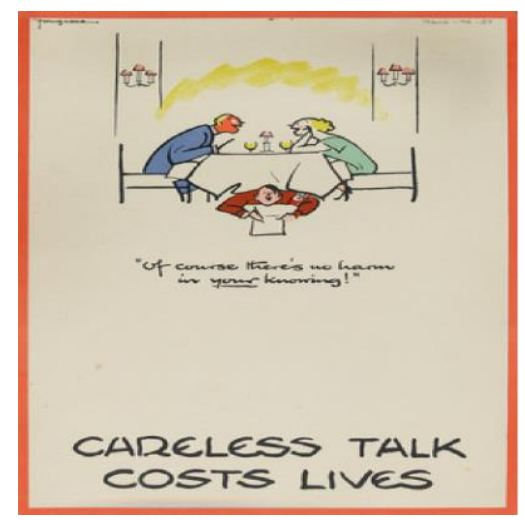

Figure 1: Image taken from the National Army Museum in London

In fact, some authors claim that "Bletchley Park may have been the best-kept secret in modern British history" (Erskine \& Smith, 2011, p. 7) and this great feeling of "having to be secured" was especially strong among those involved with government issues. That was the case of the main character of our present study, whose own existence was kept highly guarded and was not officially acknowledged until 1994. June remembers these years of her life as highly secretive:

My husband knew I was at a Section of the Foreign Office but he did not know which one or what I was doing. We never discussed it. We used to meet after work and I could not tell him where the office was or on what street, absolutely nothing .... My friends knew I was working for the Foreign Office, but they had absolutely no idea what I was doing. I am sure absolutely everybody in the country remembers that we were warned against what they called 'careless talk'. They used to have big posters on the walls and it would read 'Careless talk costs lives'. Everybody knew they must not talk about what they were doing. Not only me. Even my husband could not talk about what he was doing. He was working in a factory that made radar equipment, a very new technology in those days. I knew he was working at a factory but I had no idea what he was doing. His factory was a private company that was taken over during the war by the War Ministry, so everything was quite secretive. Everybody knew they must not talk about it. It was information that could be abused by the enemy, whether it was manufacturing of weapons, or whatever it was ... It was a great feeling of having to be secured, not giving anything away. You 
may think it was quite innocent and yet it could be abused. (June, interviewed subject)

Those who knew of the existence of the secret place and about the activities carried out within never leaked the information out to avoid everyone's hard work and effort becoming worthless. As a matter of fact, Churchill himself described the 10000 men and women who worked at BP as "the geese who laid the golden eggs and never cackled" (Andrew, 2011, p. 7). Secrecy was pledged by everyone and the authorities were determined that as few people as possible were to know what was being accomplished - even once the war was over (Briggs, 2011, p. 26).

There was complete security. We actually had to swear ... to take an oath before you could even start. We were very conscious about being highly secretive, and you never dreamt of mentioning, even to a friend, who else worked at your office, whom you had seen at the office. You didn't mention anything about anything outside the office. (June, interviewed subject)

None, therefore, would dare to discuss their work "outside its confines, let alone with family or friends in the outside world" (Taunt, 2001, p. 102). In the same way, Walter Eytan (2001) remembers this episode of his life as follows:

We were warned from the first moment never, under any circumstance, until our dying day, to reveal even by the most opaque hint what our work was; and we were taught how to handle awkward questions that might be put to us. ... Security was second nature to us; my wife said she found difficulty in marrying a man who would not tell her what he did in the war. ... By the end of the war thousands of people were working at BP, and yet the enemy never knew. (p. 57)

MI6 workers had been asked "to keep the secret forever - or so we thought then. The penalty for any breach of security was two years in prison" (Payne, 2001, p. 133). However, all tensions and isolation kept for 30 years (Payne, 2001, p. 131) were released when in the mid-1970s some of the MI6's BP and GCCS workers started to share certain details regarding their jobs with their families and friends. In this respect, Briggs (2011, p. 6) recalls how neither his Hut 6 colleague Oliver Lawn nor his wife - who had worked in BP as well - ever told each other what they had been doing before or after they met (Briggs, 2011, p. 8). Similar to this story, Andrew (2011) recalls the following memory:

A student at my Cambridge college told me how, together with his parents and his sister, he had watched the first BBC documentary 
on Bletchley Park which showed war-time Wrens (members of the Women's Royal Naval Service) operating the 'bombes' used to break the German 'Enigma' machine ciphers. At the end of the programme, his mother turned to the rest of the family and told them, 'That's where I worked. That's what I did'. Until that moment, neither her husband nor her children had had any idea that she had been a wartime codebreaker. (p. 7)

This secrecy becomes even more sensitive in what linguist scholars define as "The Translation Zone" (Apter, 2006) - the space between an original text and its translated version. According to Footitt (2010), "[t]he Translation Zone is a problematic area ... particularly so in times of war and conflict, where issues of accuracy, security and loyalty are of major concern" (p. 272).

Therefore, who is to be trusted with the translation, evaluation and analysis of highly secretive messages, from which intelligence material is to be extracted, in order to win a war?

\subsubsection{Recruitment process and trustworthiness implications within}

The use of a foreign language is required in every single step during an international conflict: gathering valuable information about the enemies, producing propaganda materials, communicating with the Allies, preparing for operations, interacting with the civilian population during occupation and liberation, questioning prisoners of war, and the like. Even though World War I had revealed certain deficiencies in the use of British policies governing the learning of languages, 20 years later Great Britain "faced much the same issues of how to engage with foreigners in war" (Footitt \& Tobia, 2013, p. 12). As a result, in 1939 a list with language specialists' names - who would be able to offer the required language services in case of need - was compiled by the Ministry of Labour. Nevertheless, the dominant presence of the French language in the British educational system at that time left resources for other languages and cultures considered strategic at the moment - such as German, Italian and Russian - relatively weak. ${ }^{4}$

A year later, in 1940, servicemen who, thanks to their language skills and knowledge, could be considered potential candidates, were busy being drafted for the front line. That is how, when the need for recruits arose, the British authorities carried out a series of recruitment waves. ${ }^{5}$ After selecting the best candidates, based on the belief that they would be trustworthy (Footitt \& Kelly, 2012, p. 24) servicemen and servicewomen, other sources had to be considered. After much deliberation, the authorities agreed that the most discreet and best 
recruitment method was word of mouth and personal recommendation "with minimum fuss and maximum dispatch" (Hinsley, 2001, p. 77). Therefore, specific networks such as public schools, London clubs and universities were targeted:

Since hardly anybody outside the organization knew anything about it, or so much as suspected its existence, I cannot imagine that anybody actually applied for employment there. (Eytan, 2001, p. 57)

Men and women were recruited from a wide variety of backgrounds, such as education, business and even entertainment, although most new recruits came from academia (Millward, 2001, p. 26). Such was the case of Leonard Foster, a Cambridge Lecturer in German, who assisted the Head of the GCCS, Alistair Denniston, in finding "men of the Professor type" (Bennett, 2001, p. 30). Denniston was mainly looking for cryptanalysts and translators (Ibid), and Foster made use of his contacts at King's College, Cambridge, that is Frank Adcock, Professor of Ancient History, and Frank Birch, a historian (Footitt \& Kelly, 2012, p. 24). Similar experience was that of Dilly Knox (King's College, Cambridge), Trevor Jones (Cambridge), Frederick Norman (King's College, London), Maxwell Newman (Manchester University), Dennis Babbage (Magdalene College), and William Millward (Dulwich College). Millward (2001) was commissioned in the RAF in August 1941 "after reading 'German with French' at Oxford, graduating in 1930, teaching at Dulwich College, [and] adding Spanish to my languages" (p. 17).

These academic recruits covered a wide range of disciplines, including mathematics, physics, languages, history and classics. However, the particular area of study was not the most important criterion, as some heads at Huts 4, 6 and 8 even preferred papyrologists (Briggs, 2011, p. 3). What was looked for and prioritized instead when recruiting was creative imagination, a well-developed critical faculty, a habit of meticulousness (Taunt, 2001, p. 111), the level of intelligence and the puzzle-solving ability displayed by each candidate, "a positioning incidentally not uncommon in university foreign language departments in that period" (Footitt \& Kelly, 2012, p. 24). A large proportion of recruits were, in fact, of university age (Briggs, 2011, p. 40; Hinsley, 2001, p. 77), including our main study subject, June; she was recruited at her own university right before finishing her undergraduate studies. She remembers this episode in her personal story with the following words:

One of my friends at St Andrews University who did the same major subjects as me, French and German, her father worked in the Secret Services (MI6) and they wanted some people who had studied German. So he literally asked her, if they sent their Recruiting Bay to the University, could she recruit some people 
studying German? ... In 1943 a lady from MI6 came to St Andrews University looking for students who had done languages. And she asked us, me and two of our friends, to go along to this interview. I think there were about six people and they took four of us. It was absolutely personal, because they had to be quite sure that we were safe. And nearly all were contacted through a personal contact. No recruitment agencies were used, because they had to be absolutely certain that people would be genuinely safe. They were recruiting by headhunting, knowing individuals. ... When we got to London we were told that we had been allocated to MI6. We were told to go and report to the Foreign Office, they spoke to us very firmly about security and we took an oath of allegiance, as anything we heard must never be mentioned outside, and then we were dispatched to our Section in London. (June, interviewed subject)

June was therefore not interviewed for a specific position at MI6, but was rather lined up for service according to her skills and later on was sent to a Section as per the necessity of the moment, her abilities, the requirements of the position and her nationality. In this line of thinking, we cannot help but notice how wars, conflict and other social catastrophes throughout the 20th and 21 st centuries were and still are a source of demand and supply of translators and interpreters (BaigorriJalón, 2003, 2010). This was also the case in World War II, a breeding ground for linguists who randomly ended up working in positions that enabled them to use the languages they had studied and learnt in all kinds of context.

\subsubsection{Subsequent recruitment waves}

With a rapid increase in the number of messages to translate (18 000 translations per month being processed in the spring of 1944 (Footitt \& Kelly, 2012, p. 22), the demand for linguists rose and a secondbest solution had to be found quickly. A new recruitment wave was carried out through radio and newspaper advertisements (Briggs, 2011, p. 4) (similar to those in the United States at the time) aimed at women with the desired language skills: "enough German to read it (not to speak nor write it)" (Footitt \& Kelly, 2002, p. 24) instead of the colloquial German and listening skills required to work in $\mathrm{Y}$ stations or listening posts. During this wave and the following ones, "women could find themselves 'hijacked' into linguist posts when it was discovered that they had Higher Certificate German ..." (Footitt \& Kelly, 2012, p. 22). Although in the beginning the ideal situation was to recruit British female citizens who had acquired their German culture and knowledge by living abroad, the authorities soon realized other candidates would have to be considered, even those whose language skills had been simply obtained inside a 
classroom - such as in June's case. Finally, when these sources dried up, civilian German refugees or German-speaking foreigners were considered, although "this move, ... was cautious - the security vetting procedure was long and stations with non-British-born employees might find their security classification downgraded ..." (Footitt \& Kelly, 2012, p. 23).

Although an element of foreignness is always a characteristic present in any situation that requires translation, during war and conflict it can bring with it certain predicaments: recruits familiar with the enemy's culture and language for any number of reasons must be placed in a variety of sensitive positions, giving them access to insightful information. As noted above, in war and conflict the Translation Zone can be especially problematic, as "issues of accuracy, security and loyalty are of major concern" (Footitt, 2010, p. 272). A similar paradox between visibility versus invisibility experienced in Interpreting Studies (see Hsieh, 2009; Inghilleri, 2003; Valero \& Gauthier, 2010) is also discerned in the dialectics between national identity versus foreignness, and security versus insider's knowledge of the enemy's culture and language (Footitt $\&$ Tobia, 2013, p. 28). Once again, languages in war and conflict prove to generate dichotomies similar to those found in other spheres of translation and interpreting. Yet, the circumstances intrinsic to war and conflict demand that both linguists and their performance guidelines or management have a certain degree of flexibility and adaptation to the context.

\subsubsection{Training in the Service}

A short section regarding the lack of training in certain offices and huts of MI6, BP and the GCCS is worth including as part of this article. In line with Bennett's (2001) words when he claims they taught themselves "the job of intelligence officers tolerably well" (p. 31), June confirms the fact that no training was offered at her MI6 Section, partly due to a lack of time:

We were thrown fresh into it. We had to use our wetsuit [laughs]. We knew what was happening. ... Our knowledge was very limited, but enough. ... All had to be done terribly quickly, as you can imagine. It was very easy to make errors, little errors just in the language. (June, interviewed subject)

Similarly to other spheres of translation and interpreting activity in which the law of supply and demand tends to rule triadic encounters, untrained linguists were hired ad hoc (see Baigorri-Jalón, 2010; Flores, Abreu, Barone, Bachur, \& Lin, 2012; Meeuwesen, Twilt, ten Thije, \& Harmsen, 2010; Ortega Herráez \& Foulquié Rubio, 2008) -conditions during war 
require this law to prevail (Gómez-Amich, 2013, p. 17). It is, however, arguable, that some recruits working at BP sections were "ill-qualified" as Bennett (2001, p. 31) described himself:

Translating was more complicated than perhaps it sounds. Some enemy messages, once deciphered, were readable enough, in straightforward German which could be translated into English with ease. As often as not, however, there would be difficulties which ... took a good deal of ingenuity and experience to overcome.... [T] the translators performed miracles in reconstructing corrupt texts and making them yield sense in English.” (Eytan, 2001, p. 59)

Some other authors claim that the contribution of these men and women can be regarded "as a highly successful and significant operation of war" (Taunt, 2001, p. 112), since all those years of work were "a triumph of integrity for the thousands of people involved" (Payne, 2001, p. 137).

Once again, in times of war and conflict it is necessary to introduce certain measures that in other contexts would not have been appropriate. As June herself mentions, the sink-or-swim line of thought becomes ever present and translators - and interpreters - need their "wetsuits", acquiring resources and skills along the way, based on practice and assistance from other colleagues.

\subsubsection{Linguists' tasks and duties}

BP's first break into German code took place in 1940 as a result of Alan Turing's collaboration with, among others, a group of Polish mathematicians, including the cryptanalyst Marian Rejewski. The Poles' success in breaking the code was assisted by the Enigma manuals sold to the French Government by the spy Hans Tylo Schmidt, codenamed "Asche" (Smith, 2011).

Although some writers have argued that the Allies "could copy only a limited number of messages ... determined by priorities" (Hanyok, 2005 , p. 152), the undeniable truth is that BP not only had to deal with "the breaking of individual messages but with the total output of an intricate communications system" (Briggs, 2011, p. 17). Therefore, in order to obtain intelligence that could be used by the Allies, "four thousand German high-grade signals a day, with slightly smaller numbers of Italian and Japanese signals" were intercepted and read (Hinsley \& Stripp, 2011, p. v). Once intercepted on radio, messages had to be properly decrypted into Italian, German or Japanese (Briggs, 2011, p. 5) and only after that could the translation-evaluation-analysis process start.

According to Millward (2003, p. 20), decrypted messages were submitted to a process that comprised emendation, translation, evaluation, 
commenting and signal drafting. The responsibilities of each step were shared between the Watchkeeper, the Number 1, the Adviser and the Duty Officer. Emendation and translation were the responsibility of the Watchkeeper, whose team would receive pieces of paper from Hut 6 containing, on one side, the original encoded text and, on the other, the decoded text, organized into five-letter groups. Millward (2001) explains:

"Emendation" meant the division of the groups into German words or numbers, etc., and as far as possible the reading of corrupt passages and the filling of gaps ... The next process was translation. This was mostly straightforward. New technical terms sometimes gave trouble. We had our backroom language expert in Trevor Jones, and he maintained a glossary of new terms as they appeared, he researched their meaning. Just occasionally he was defeated. I can remember his going round for several days with a worried look on his face murmuring Drehkreuzachse. (pp. 20-21)

Briggs (2011), in turn, summarizes the process as follows:

The Hut Three Watch consisted of about a dozen people sitting $^{6}$ round a semi-circular table, with the head of the Watch sitting inside the semi-circle facing his colleagues. All of them knew German. When messages arrived from Hut Six, a member of the Hut Three Watch took each one, separated the five-letter groups into German words by pencil strokes and wrote down an English version of the text on a separate piece of paper. The head of the watch meticulously checked the papers that they had given him and then, in turn, passed them on to the air and military advisors, working in pairs, who sat at an adjacent rectangular table. (p. 90)

Once the emendation and translation tasks were completed, the Watchkeeper would pass the work to Number 1, who would carefully check it and hand it over to the Adviser. Adviser's main tasks were, first, to decide whether the message contained any new intelligence and its level of significance and, secondly, to draw up a version and pass it to Commands. The next step would be to pass the whole package to the Duty Officer, who was responsible for all releases (Millward, 2001, pp. 20-22) and whose most important duties were to ensure the papers faithfully reproduced the sense of the original German message and also to make sure that the draft did not imply more or less than was actually warranted (Bennett, 2001, p. 33).

Further on, all intelligence extracted from any intercepted and, later on, decrypted messages was revised and recorded for future reference and use. An essential part of this "team effort" (Briggs, 2011, p. 5) was the position held by our main study subject for two-and-a-half years of her life. June summarizes her tasks and duties at MI6 as follows: 
The British had broken the code of the German Intelligence Services. Highly secret messages came in German to Bletchley Park and then it came to our office. ... I was in the room in which all messages came into. And they had to be recorded all by hand, because there were no machines in those days. We recorded all these messages on cards so each individual German spy had a card, a thick pile of cards actually, some of the important ones. Anything that came with that person's name on it would have to be written down in that card. And anybody else connected with them, because that's how they managed to find out what was going on, where they were moving people to, and that kind of thing. By the time it got to me it was in English. The point of my languages was that I could check because sometimes the meaning would be difficult for the people in the big office to do it. And I would think 'that person cannot be doing that', then I would go back to the German and I would be able to check and correct. (June, interviewed subject)

According to historian and codebreaker, Peter Calvocoressi, the Watch in Hut 3 - "responsible for translating and elucidating the German Air Force and Army decrypts" (Thomas, 2001, p. 45) - received a paper similar in size to a Post Office telegram containing the deciphered Enigma material from Hut 6 . Hut 3 would first meticulously translate and interpret the messages, in order to categorize them later on in factual indexes ${ }^{7}$ (Rayward \& Bowden, 2004, p. 292), then summarize them (Briggs, 2011, p. 5) and transmit them abroad. That was partly June's main task at MI6 and she recalls it in the following words:

Our knowledge was very limited, but enough. If something did not seem to fall in place, we would have to go to the original German message to see if it had been correctly translated by the people in Bletchley Park. That was the main thing. We had to do that quite frequently. Something didn't fit on the cards, something didn't fit about the movements ... We would go back and see if they had slipped something out. We did that very often, but we were very good. ... Making sure the right message would come through. All had to be done terribly quickly, as you can imagine. It was very easy to make errors, little errors just in the language." (June, interviewed subject)

Thomas (2001), in turn, praises the talent of the indexers working for SIS during the war years:

... they were always on duty, keeping records of every detail that may be needed for reference in solving some future conundrum. Often, with a gentle word, they would guide the harassed watchkeeper to the solution that had been eluding him. (p. 49) 
Therefore, as evidence proves and as noted by Millward (2003, p. 20) as well as by Footitt and Kelly (2012, p. 32), the evaluation and analysis of translated messages had to be vital parts of the process, which in turn makes the distinction between intelligence analysis and translation "essentially notional" (Footitt \& Kelly, 2012, p. 12). In order to avoid mistranslations, misinterpretations, misunderstandings and their potentially critical consequences "each piece of raw intelligence had to be related to its overall cultural background in order to be understood and properly analyzed" (Footitt \& Kelly, 2012, p. 34).

\section{Conclusions}

Even though World War II was "the most astonishing and unpredictable story ever written" (Bulletin No. 78, in Briggs, 2011, p 134), as with all other great stories, it did come to an end. On 8 May 1945, Commander Travis sent a message praising everyone's work and triumphs and claiming that exact moment to be their "finest hour". Everything had reached an end, everything except for one: the secretiveness. It was still paramount that everyone remained as secretive in peacetime as they had been in wartime (Briggs, 2001, p. 126).

Although SIS's story "is essentially one of people, [of] men and women who served it across the world" (Jeffery, 2010, p. ix), it was not until many decades after the war ended that BP's existence was officially acknowledged and veterans' contributions publicly honoured. The reason for this, besides security, may share certain similarities with an issue that translators and interpreters must face daily around the world, which is that:

If a crypthographer is unsuccessful, for whatever reason, he tends to be forgotten or possibly misjudged. If he is consistently successful, his work may be taken for granted or supposed much easier than it actually is. (Morris, 2001, p. 243)

Although veterans who worked in a variety of stations recall this time of history as "the most interesting three years of my life" (June, interviewed subject) and consider themselves "extraordinarily lucky to have found myself in that particular job at that time" (Milner-Barry, 2001, p. 97), the lack of recognition caused them suffering for decades - similar to what linguists are exposed to in a variety of contexts. As a result, some authors felt encouraged to claim how sad and frustrating the situation must have been for everyone involved (Briggs, 2011, p. 27).

I hope this article takes the form of a declaration of recognition of the hard work, contribution and triumphs achieved by anyone and everyone involved in the SIS activities during World War II. Allow me, however, to specially mention linguists and indexers who, due to their 
knowledge in foreign languages, saw themselves "kidnapped" and assigned to random positions that required broad adaptation and flexibility regarding tasks and duties similar to that required from linguists in all kinds of conflict-related setting.

Once again, we can see that conflict and war create particular contexts in which a linguist's role must be reconciled between the ideology of Translation and Interpreting Studies and their actual performance in real situations. Therefore, discrepancies between ideology and real practice do exist and must be considered as an ideal opportunity for researchers to "re-examine and re-conceptualize the necessary changes in the theory building of translation and interpreting studies" (Hsieh, 2002, p. 408) in order to "make recommendations for what constitutes appropriate interpreter behaviour (Mason, 2000, p. 220). This they should do while keeping in mind the wide variety of settings in which language services are needed. It is in this way that the complex role linguists must play daily in conflict-related settings can somehow be adapted to the contextual characteristics they must deal with in these scenarios.

\section{References}

Andrew, C. (2011). Bletchley Park in pre-war perspective. In R. Erskine \& M. Smith (Eds.), The Bletchley Park codebreakers (pp. 1-12). London: Biteback.

Apter, E. (2006). The translation zone. Princeton, NJ: Princeton University Press.

Baigorri-Jalón, J. (2003). Guerras, extremos, intérpretes. In R. Muñoz Martín (Ed.),

I AIETI. Actas del Congreso Internacional de la Asociación Ibérica de Estudios de Traducción e Interpretación, vol. II (pp. 159-176). Granada: AIETI.

Baigorri-Jalón, J. (2010). Wars, languages and the roles of interpreters. Les liaisons dangereuses: Langues, traduction, interpretation (pp. 173-204). Beirut: Saint Joseph University.

Bennett, R. (2001). The duty officer. In F. H. Hinsley \& A. Stripp (Eds.), Codebreakers: The inside story of Bletchley Park (pp. 17-29). Oxford: Oxford University Press.

Briggs, A. (2011). Secret days: Code-breaking in Bletchley Park. Barnsley: Frontline Books.

Calvocoressi, P. (1981). Top secret ultra. London: Sphere Books.

Currer-Briggs, N. (2001). Army Ultra's poor relations, In F. H. Hinsley \& A. Stripp (Eds.), Codebreakers: The inside story of Bletchley Park (pp. 195-208). Oxford: Oxford University Press.

Dryden, H. (2001). Recollections of Bletchley Park, France and Cairo. In F. H. Hinsley \& A. Stripp (Eds.), Codebreakers: The inside story of Bletchley Park (pp. 195-208). Oxford: Oxford University Press. 
Eytan, W. (2001). The Z Watch in Hut 4, Part II. In F. H. Hinsley \& A. Stripp (Eds.), Codebreakers: The inside story of Bletchley Park (pp. 57-60). Oxford: Oxford University Press.

Flores G, Abreu M., Barone C. P., Bachur R., \& Lin H. (2012). Errors of medical interpretation and their potential clinical consequences: A comparison of professional versus ad hoc versus no interpreters. Annals of Emergency Medicine, 60(5), 545-553.

Footitt, H. A. (2010). Languages at war: Cultural preparations for the liberation of Western Europe. Journal of War and Culture Studies, 3(1), 109-121.

Footitt, H. A., \& Kelly, M. (2012). Languages and the military: Alliances, occupation and peace building. Basingstoke: Palgrave Macmillan.

Footitt, H., \& Tobia, S. (2013). WarTalk: Foreign languages and the British war effort in Europe, 1940-47. Basingstoke: Palgrave Macmillan.

Gómez-Amich, M. (2013). The vital role of conflict interpreters. Nawa Journal of Languages and Communication, 7 (2), 15-28.

Hanyok, R. J. (2005). Eavesdropping on hell: Historical guide to Western communications intelligence and the Holocaust, 1939-1945. New York, NY: Center for Cryptologic History, National Security Agency.

Hinsley, F. H. (2001). Bletchley Park, Admiralty and naval Enigma. In F. H. Hinsley \& A. Stripp (Eds.) Codebreakers: The inside story of Bletchley Park (pp. 7780). Oxford: Oxford University Press.

Hinsley, F. H. \& Stripp, A. (Eds.). (2001). Codebreakers: The inside story of Bletchley Park. Oxford: Oxford University Press.

Hsieh, E. (2002). Necessary changes in translation ideology. Studies of Translation and Interpretation, 7, 399-435.

Hsieh, E. (2009). Bilingual health communication: Medical interpreter's construction of a mediator role. In D. Brashers \& D. Goldsmith (Eds.), Communicating to manage health and illness (pp. 135-160). New York, NY: Routledge.

Inghilleri, M. (2003). Habitus, field and discourse: Interpreting in a socially situated activity, Target, 15(2), 243-268.

Jeffery, K. (2010). MI6: The history of the secret intelligence service 1909-1949. London: Bloomsbury.

Kupcikas, K. (2013). The importance of intelligence to international security. Retrieved 8 November 2015, from http://www.eir.info/2013/11/08/ importance-of-intelligence-to-international-security/

Lewin, R. (1978). Ultra goes to war: The secret story. London: Hutchinson.

Mason, I. (2000). Models and methods in dialogue interpreting research. In M. Olohan (Ed.), Intercultural faultines (pp. 215-232) Manchester: St. Jerome.

Meeuwesen, L., Twilt S., ten Thije, J. D., \& Harmsen, H. (2010). Ne diyor? (What does she say?): Informal interpreting in general practice. Patient Education and Counseling, 81, 198-203.

Millward, W. (2001). Life in and out of Hut 3. In F. H. Hinsley \& A. Stripp (Eds.), Codebreakers: The inside story of Bletchley Park (pp. 17-29). Oxford: Oxford University Press. 
Milner-Barry, S. (2001). Hut 6: Early days. In F. H. Hinsley \& A. Stripp (Eds.), Codebreakers: The inside story of Bletchley Park (pp. 89-99) Oxford: Oxford University Press.

Morris, C. (2001). Navy Ultra's poor relations. In F. H. Hinsley \& A. Stripp (Eds.), Codebreakers: The inside story of Bletchley Park (pp. 231-245). Oxford: Oxford University Press.

National Army Museum in London Retrieved 5 July 2015 from http://prints.nationalarmy museum.ac.uk/image/378918/cyril-kenneth bird-careless-talk-costslives-1940.

NATO Allied joint doctrine for countering-improvised explosive devices. Retrieved 29 November 2016 from https:/www.scribd.com/doc/180718058/NATOAJP-3-15-B-Allied-Joint-Doctrine-for-Countering-Improvised-Devices-2013uploaded-by-Richard-J-Campbell

Ortega Herráez, J. M., \& Foulquié Rubio, A. I. (2008). Interpreting in police settings in Spain: Service provider's and interpreters' perspectives. In A. Martin \& C. Valero Garcés (Eds.), Crossing borders in community interpreting: Definitions and dilemmas (pp. 123-146) Amsterdam: John Benjamins.

Paterson, M. (2008). Voices of the code breaker: Personal accounts of the secret heroes of World War II. Cincinnati, OH: David \& Charles.

Payne, D. (2001). The bombes. In F. H. Hinsley \& A. Stripp (Eds.), Codebreakers: The inside story of Bletchley Park (pp. 132-138). Oxford: Oxford University Press.

Rayward W. B., \& Bowden M. E. (Eds.). (2004). The history and heritage of scientific and technological information systems: Proceedings of the 2002 Conference. Medford, NJ: Information Today.

Smith, M. (2011). The secrets of Station X: How the Bletchley Park codebreakers helped win the war. London: Biteback.

Taunt, D. (2001). Hut 6: 1941-1945. In F. H. Hinsley \& A. Stripp (Eds.), Codebreakers: The inside story of Bletchley Park (pp. 100-112). Oxford: Oxford University Press.

Thomas, E. (2001). A Naval officer in Hut 3. In F. H. Hinsley \& A. Stripp (Eds.), Codebreakers: The inside story of Bletchley Park (pp. 41-49). Oxford: Oxford University Press.

Valero Garcés, C., \& Gauthier Blasi, L (2010). Bourdieu y la traducción e interpretación en los servicios públicos: Hacia una teoría social, MonTI, 2, 97 117.

Welchman, G. (1982). The Hut Six story: Breaking the Enigma codes. London: Allen Lane. 
1 According to the SIS official website, “"MI6' has become an almost interchangeable title for SIS, at least in the minds of those outside the Service. The origins of the use of this other title are to be found in the late 1930s when it was adopted as a flag of convenience for SIS. It was used extensively during the Second World War". This will be the case, as I will be referring to the SIS as MI6 throughout this article.

2 The code-breaking triumph was possible due to the Germans not enforcing a strict cryptographic discipline. The author claims that German cipher clerks were careless, lazy and too methodological and courteous, repeating and reciphering messages as well as addressing recipients with their full rank, title, name or unit number and its location (CurrerBriggs, 2001, pp. 213-214).

3 Although 'decrypted' is the modern term, coined in 1940s, this article uses "decoded" and "decrypted" as interchangeable terms.

4 The number of students taking French at the school public examination stages was up to eight times higher than those sitting in German (Footitt \& Tobia, 2013, p. 16).

5 Some recruitment waves were specifically aimed at linguists with a high command of German language who had not been destined for combat. For such language positions, the British authorities decided to recruit servicewomen who could be easily transferred to a new position, i.e. WAAF (Women's Auxiliary Air Force) German-speakers and WRNS (Women's Royal Naval Service).

6 This system had its origins in 1941. At first there were only four men whose task was to "draw the full meaning out of batches of decrypted messages sent to them in cardboard boxes from Hut 6, translate them into plain English and transmit what messages they thought relevant on to London ..." (Briggs, 2011, p. 91).

7 Such indexes were categorized into Air Index, Military (or Army) Index, Naval Index Specialist and Indexes (Rayward \& Bowden, 2004, pp. 292-294). 